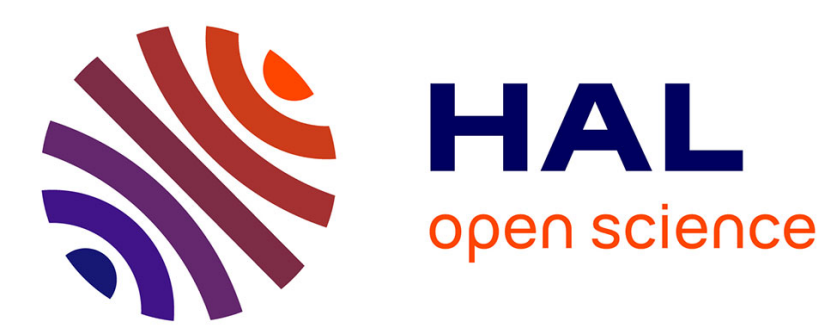

\title{
ON THE ATOMIC STRUCTURE OF LIQUID GaAs
}

\author{
Claire Bergman, C. Bichara, P. Chieux, J. Gaspard
}

\section{To cite this version:}

Claire Bergman, C. Bichara, P. Chieux, J. Gaspard. ON THE ATOMIC STRUCTURE OF LIQUID

GaAs. Journal de Physique Colloques, 1985, 46 (C8), pp.C8-97-C8-100. 10.1051/jphyscol:1985811 . jpa-00225152

\section{HAL Id: jpa-00225152 https://hal.science/jpa-00225152}

Submitted on 1 Jan 1985

HAL is a multi-disciplinary open access archive for the deposit and dissemination of scientific research documents, whether they are published or not. The documents may come from teaching and research institutions in France or abroad, or from public or private research centers.
L'archive ouverte pluridisciplinaire HAL, est destinée au dépôt et à la diffusion de documents scientifiques de niveau recherche, publiés ou non, émanant des établissements d'enseignement et de recherche français ou étrangers, des laboratoires publics ou privés. 


\author{
C. Bergman, C. Bichara, P. Chieux ${ }^{\star}$ and J.P. Gaspard $\star \star$ \\ Centre de Thermodynamique et de Microcalorimétrie du CNRS, \\ 26 me du 141e R.I.A., 13003 Marseizle, France \\ *Institut Laue Langevin,.B.P. 156X, 38042 Grenoble, France \\ * Université de Liège, Institut de Physique (B5), 4000 Sart Tilman, \\ Beigium
}

\begin{abstract}
Rếsumé - Comme pour $\mathrm{Si}$ et $\mathrm{Ge}$, les propriêtés de GaAs changent fortement à la fusion : la phase liquide possède une conduction métallique et sa densité est supérieureà la phase cristalline semiconductrice. De plus, l'entropie de fur sion est anormalement élevée. Les propriétés de la phase liquide peuvent être expliquées parsa structure. Nous avons mesuré le facteur de structure total de GaAs Iiquide juste au-dessus de son point de fusion ( $T=1250^{\circ} \mathrm{C}$ ) par diffraction de neutrons sur le diffractomètre D4B à 1'ILI de Grenoble. Le facteur de structure et la fonction de corrélation de paires sont semblables à ceux du silicium et du germanium. Cependant, le nombre de coordination mesuré est . 5,5 $\pm 0,5$, inférieur à la valeur correspondante $(6,4)$ de $\mathrm{Si}$ et Ge. Différents modèles de structure sont discutés.
\end{abstract}

Abstract - Like Si and Ge, the properties of GaAs change drastica11y upon melting : the molten phase shows a metaliic conduction and its density is larger than in semiconducting crystalline phase. In addition, the entropy of melting is anomalously large. The liquid phase properties of GaAs can be explained by its structure. We have measured the total structure factor of liquid GaAs just above its melting temperature $\left(\mathrm{T}=1250^{\circ} \mathrm{C}\right)$ by neutron diffraction on the D4B diffractometer at the ILL (Grenoble). The structure factor and pair correlation function are similar to those of $\mathrm{Si}$ and Ge. However the coordination number is $5.5 \pm 0.5$, lower than the corresponding value (6.4) for $\mathrm{Si}$ and Ge. Different structural models are discussed.

\title{
I - INTRODUCTION
}

The crystalline structures of light group IV elements ( $\mathrm{Si}, \mathrm{Ge}, \alpha-\mathrm{Sn}$ ) and their isoelectronic compounds (III-V and II-VI) are fourfold coordinated at low temperature and low pressure. These structures are traditionally explained by the formation of $\mathrm{sp}^{3}$ hybrids that just point along the direction of the bonds in the diamond or würzite structures. However, when pressure or temperature is increased, the coordination number increases from 4. to 6 ( $\beta-\mathrm{Sn}$ structure) and the sixfold coordinated phase shows a metallic conduction. In addition, when $\mathrm{Si}$ or $\mathrm{Ge}$ melts, their coordination number increases to $6.4 / 1,2 /$ and the liquid phase is also metallic. In this study we analyse the structure of molten GaAs (isoelectronic to Si). It is known that me1ting of GaAs is accompanied by a $11 \%$ increase of density /3/. This results from a large increase in the coordination number $(4 \rightarrow 5.5)$ although the bond length is also. increased.

\section{II - EXPERIMENTS}

GaAs alloys at 50 at \% were prepared from pure metals and filled into cylindrical containers which were made from a 6-8.2 mm quartz tube. Before the diffraction experiment, we verified that GaAs didn't react with the quartz at the experimental temperature $\left(1250^{\circ} \mathrm{C}\right)$. 
The measurements were carried out on the neutron diffraction spectrometer $D 4 \mathrm{~B}$ located at the Institut Max Von Laue-Paul Langevin, Grenoble, France, operating at a wavelength $\lambda=0.703 \AA$. The data were corrected for the quartz container, the $0.1 \mathrm{~mm}$ thick vanadium foil heater and the sample self absorption in the usual way $/ 4 /$. An unexplained time evolution of the sample scattering pattern rendered more difficult the analysis. However, thanks to the fact that we had performed three consecutive scans, we could exploit a large part of the data with a fair degree of confidence after a small correction ( 3 to $4 \%$ over a full scan) for a linear decrease of the intensities with time. The data were then corrected, as usual, for inelasticity effects, multiple scattering and incoherent scattering $/ 4 /$. The highest angular values $14<k<16 \AA^{-1}$ which were structureless but very slightly affected by an apparent systematic error $(\sim 1 \%)$ were discarded.

\section{III - EXPERIMENTAL RESULTS}

\section{i) Structure factor $\mathrm{S}(\mathrm{k})$}

The structure factor is presented in Fig. 1. One clearly sees damped oscillations up to $14 \AA^{-1}$. The first peak is split into two peaks at $k_{1}=2.5 \AA^{-1}$ and $k_{1}^{1} \simeq 3.1 \AA^{-1}$; the second peak is situated at $k_{2}=5.3 \AA^{-1}$. Let us notice that the ratio $k_{2} / k_{1}$ is slightly larger than 2, the observed value in $\mathrm{Si}$ and $\mathrm{Ge}$, which is a rather unusual value; most systems indeed present a ratio $\mathrm{k}_{2} / \mathrm{k}_{1}$, close to or smaller than 1.8 . According to $/ 5 /$, in the case of amorphous semiconductors, this ratio seems to be sensitive to the medium range order (in that case, the percentage of edd membered rings in the structure).

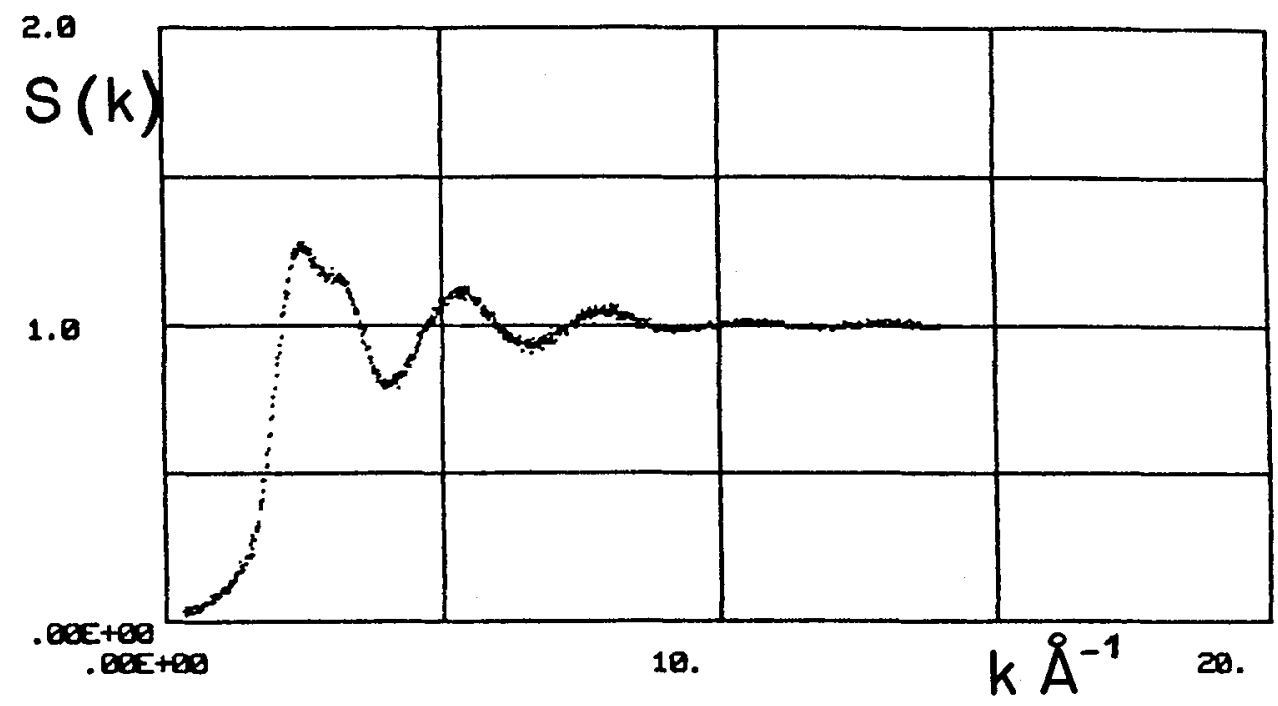

Fig, 1 - Total structure factor, $\mathrm{S}(\mathrm{k})$, of $\mathrm{Ga}_{0.50^{\mathrm{As}}} 0.50$ in the liquid state.

ii) Thermodynamic limit

The long wavelength limit $(k \rightarrow 0)$ of the structure factor is related to the macroscopic thermodynamic properties of the system. In the case of a binary alloy, this involves three quantities $/ 6 /$, the isothermal compressibility, the difference in partial molar volumes and the second derivative of the free energy versus concentration.

Because of the interest in semiconducting industry, the thermodynamic properties of 
the GaAs system havebeen widely studied in the solid state but no experimental study in the liquid state has been reported in the literature. A recent critical analysis /7/ based on experimental determination of the phase diagram, the thermodynamic properties of the solid compound and vapour pressure measurements presents an analytical expression for the excess free energy of formation of the liquid phase $\mathrm{GaAs}_{\mathrm{X}} \mathrm{x}_{1-\mathrm{x}}$

$$
\Delta \mathrm{G}^{\mathrm{E}}=376.2-5.983 \mathrm{~T} \mathrm{cal} \mathrm{mol}-1
$$

This representation implies a regular behaviour for the melt ; from these coefficients, a value of 0.010 is obtained for $\mathrm{S}(0)$.

On the other hand, the experimental determination of $\mathrm{S}(0)$ from the structure factor data yields a value of 0.03 at the lowest after a supplementary rough isotropic correction for the double scattering between sample and container. This discrepancy can be explained either by an underestimate of the neutron incoherent cross sections or an overestimate of the deviation from ideality in the thermodynamic properties. According to the literature, both reasons can be considered and new experimental information is needed. Concerning the thermodynamic behaviour, a small value of the excess functions of mixing suggests a weak chemical short range order.

\section{iii) Paix correlation function}

The pair correlation function $G(r)$ or $4 \pi r \rho_{0}(g(r)-1)$ shows an asymmetric peak at $2.56 \AA$ with a shoulder at about $2.96 \AA$, above which the structure is very weak except for a peak at about $6 \AA$ (see Fig. 2).

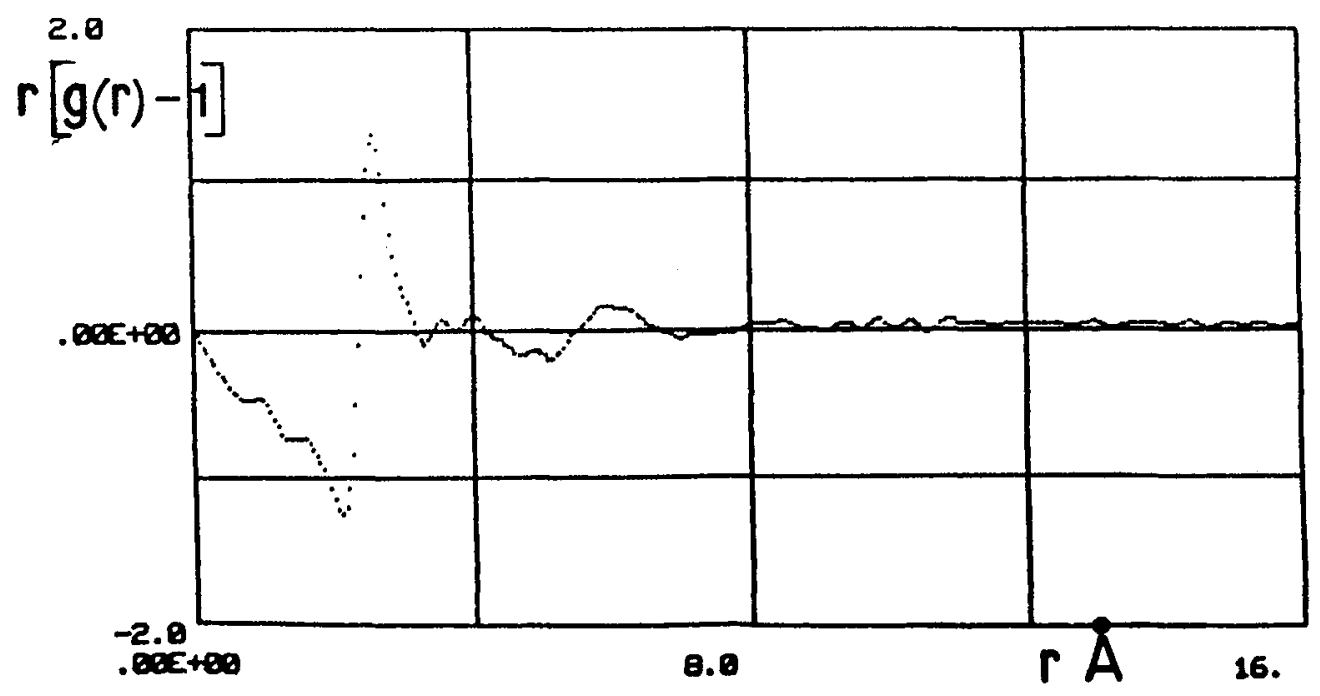

Fig. 2 - Pair correlation function of $\mathrm{Ga} 0.50^{\mathrm{As}} 0.50$ in the liquid state.

The absence of oscillations above the first nearest neighbours is quite understandable in the weakly compact structures. By contrast to compact structures (e.g. normal liquid metals) where the atoms are ordered shell by shell so that $g(r)$ oscillates up to 4 or 5 nearest neighbour distances, in liquid GaAs, as there are only $\sim 6$ nearest neighbours in the first coordination shell, it results to empty interstitial space and disruption of the multilayer shell ordering. Consequently $g(r)$ does not show well defined oscillations above the nearest neighbour separation. The increase in nearest neighbour distance upon melting (crystal : $2.448 \AA$, liquid : $2.56 \AA$ ) is $4.5 \%$ for GaAs (a value to compare with $6 \%$ for $\mathrm{Si}$ and $15 \%$ for $\mathrm{Ge}$ ). This is consistent with quantum mechanical calculations that predict that the 
interatomic distance gets larger when the coordination number increases.

As usual in liquids, the coordination number is subject to some uncertainty in its determination. We fit the first peak of $g(r)$ with two gaussian curves, the area under which is determined. The fairly narrow gaussian curve centered at $2.56 \AA$ is largely insensitive to the $k$ cutoff value; it gives a fraction of the coordination number which is $3 \pm 0.15$. By contrast, the second gaussian curve is poorly identified and in particular, its parameters are strongly affected by the data between 10.5 and $16 \AA^{-1}$. At this stage of the analysis, we conclude that the total coordination number is between 5.3 and 6 . Let us notice that a brute force integration of $G(x)$ up to $3.04 \AA$ gives 5.3 .

\section{IV - MODELS}

To the authors' knowledge, there is no microscopic models of molten Si or Ge (e.g. similar to the Polk model for tetracoordinated amorphous $\mathrm{Si}$ ). Many authors have discussed the peculiar structure of $g(r)$ for $S i$ and Ge. They divide into two groups : some authors assume that two types of $\mathrm{Si}$ (or $\mathrm{Ge}$ ) atoms are present in the melt : covalent units with coordination 4 and "metallic" Si atoms with a large coordination $(\sim 12)$ so that 6.4 is a weighted average of both types of atoms. We reject this hypothesis as long as they are no physical measurements showing the existence of these two species of $\mathrm{Si}$. Uther authors argue that liquid $\mathrm{Si}$ should be related to a distorted simple cubic (s.c) or B-Sn structure. This is supported by the fact that the $\mathrm{p}$ electrons play a central role in the structure. As they have 6 lobes pointing at right angle, the maximum stability corresponds to a coordination number of six in a s.c. or $\beta-S n$ structure. We believe that the GaAs structure is also related to the $B-\mathrm{Sn}$ structure rather than the s.c. This is supported by the fact that the first peak of $g(r)$ is asymmetric and can be analysed into two peaks (2.56 and 2.96 $\AA$ ) which would correspond to the two nearest neighbour distances (with coordination numbers 4 and 2 respectively) of the $\beta$-Sn structure.

The electronic properties of molten $\mathrm{Si}$ and Ge are quite consistent with an hexacoordinated structure indeed calculations have shown $/ 8 /$ that the s.c. and $\beta-\mathrm{Sn}$ structure give a metallic type cohesion with a finite density of states at the Fermi energy.

Let us endly recall that the entropy of melting is anomalously high in the group IV elements and the III-V (and to some extend the group II-VI) compounds. For example for $\mathrm{Si}$ and $\mathrm{Ge}, \mathrm{S}_{\mathrm{f}}=7.2 \mathrm{cal} / \mathrm{at} . \mathrm{g}$. whilst for GaAs, $\mathrm{S}_{\mathrm{f}}=8.6 \mathrm{cal} / \mathrm{at} . \mathrm{g}$. The value is reduced for $\mathrm{ZnTe}$ to $5.8 \mathrm{cal} / \mathrm{at} . \mathrm{g}$.

The leading contribution to the entropy of melting of Si originates in the electronic delocalization in the metaliic molten phase /9/. The electronegativity difference should decrease the delocalization of the electrons (they tend to remain near the most electronegative element) as it does for $\mathrm{ZnTe}$, but the effect does not seem to be important for GaAs.

\section{REFERENCES}

/1/ Gabathuler, J.P. and Steeb, S., Z. Naturf. 34 A (1979) 1314.

/2/ Bellissent-Fune1, M.C. and Bellissent, R., J. Non-Cryst. Solids 65 (1983) 383.

/3/ Glazov, V.M., Chizhevskaya, S.N. and Glagoleva, N.N. in "Liquid semiconductors", Plenum Press (1969) 124.

/4/ Eisenberg, S., Jal, J.F., Dupuy, J., Chieux, P. and Knoll, W., Phil. Mag. A 46 (2) (1982) 195

15/ Dixmier, J., Gheorghiu, A. and Theye M.L., J. Phys. C, 17 (1984) 2271.

16/ Bhatia, A.B. and Thornton D.E., Phys. Rev. B 2 (1970) 3004. Bhatia A.B., Hargrove W.H. and Thornton D.E., Phys. Rev. B 9 (1974) 435 .

17/ Tmar, M., Gabrie1, A., Chatillon, C. and Ansara, I., J. Cryst. Growth 68 (1984) 557.

/8/ Gaspard, J.P., Lambin, P., Mouttet, C. and Vigneron, J.P., Phil. Mag. B 50 (1984) 103.

/9/ Chakraverty, B.K., J. Phys. Chem. Solids 30 (1969) 454. 